\title{
Awareness of influenza and pneumococcal vaccines in diabetic patients
}

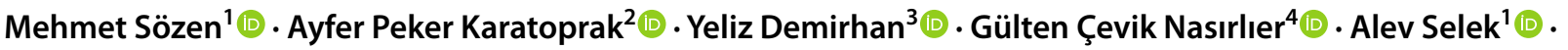

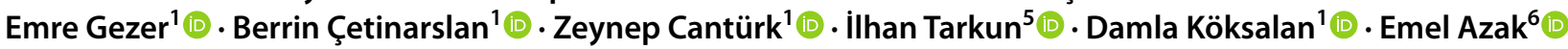

Received: 20 March 2021 / Accepted: 27 April 2021 / Published online: 7 May 2021

(c) Springer Nature Switzerland AG 2021

\begin{abstract}
Purpose In our study, it was aimed to evaluate the awareness of diabetic patients about vaccination status and vaccines. Methods This cross-sectional study was conducted between January 2019 and February 2019. A survey questioning the level of knowledge about and vaccination status for influenza and pneumonia vaccines was applied by face-to-face interviews with patients with diabetes mellitus who admitted to the diabetes outpatient clinic. All results were evaluated with SPSS-20.0.

Results A total of 202 patients [ 66 male (32.7\%) and 136 female (67.3\%) patients; with a mean age of $57.7 \pm 11.3$ years and mean duration of diabetes $10.7 \pm 7.9$ years] were recruited in the study. Majority of the patients $(92.6 \%)$ were type $2 \mathrm{DM}$ patients. 59.4\% of the patients had never been vaccinated. The rate of those who had pneumonia vaccine was very low, only $14.7 \%$. The vast majority of the patients had knowledge about vaccines and their most common source of information was nurses. 53\% of patients believed that diabetic patients should be vaccinated regularly. $16.8 \%$ of the patients were reluctant to have the recommended vaccine. The factor with greatest impact on this was that they did not consider the vaccine necessary. $52.5 \%$ of the patients recommended to be vaccinated had the recommended vaccine. $26.4 \%$ of the patients who were not enthusiastic about the recommended vaccine had pneumococcal vaccine after being informed about the vaccine.

Conclusion It was observed that the information given about vaccines positively affected the vaccination rate. The main barrier to vaccination was the lack of information about the need for influenza vaccination. Designing strategies and training programs for healthcare professionals and patients should be the main goal to improve vaccination coverage and vaccination rates.
\end{abstract}

Keywords Pneumococcal Vaccine $\cdot$ Diabetes Mellitus · Awareness · Vaccination Rate

Mehmet Sözen

mehmetsozen07@gmail.com

1 Department of Endocrinology and Metabolism, Faculty of Medicine, Kocaeli University, Kocaeli, Turkey

2 Kocaeli Vocational School of Health Services, Kocaeli University, Kocaeli, Turkey

3 Diabetes Outpatient Clinic, Kocaeli University Research and Application Hospital, Kocaeli, Turkey

4 Department of History of Medicine and Ethics, Kocaeli University Institute of Health Sciences, Kocaeli, Turkey

5 Department of Endocrinology and Metabolism, Anadolu Medical Center, Kocaeli, Turkey

6 Department of Infectious Diseases and Clinical Microbiology, Faculty of Medicine, Kocaeli University, Kocaeli, Turkey

\section{Introduction}

Vaccination programs, one of the most effective public health interventions to reduce or eliminate the burden of communicable diseases, have fallen far below targeted levels even in the most developed countries. Routine vaccination is recommended by various organizations, as it is effective in reducing the risk of influenza and invasive pneumococcal disease in high-risk individuals [1,2]. Since invasive pneumococcal diseases caused by streptococcus pneumoniae among diabetic individuals are associated with increased morbidity and mortality, vaccination has gained importance in these individuals $[1,3]$. Therefore, governments have adopted routine vaccination programs as a health policy, and recommendations for routine pneumococcal vaccination are currently available in 29 European countries [4]. In Turkey, the ministry of health included the conjugate 
pneumococcal vaccine (PCV13) within the scope of the expanded immunization program in 2016 , and included all diabetic patients, regardless of age, in its routine vaccination program. In guidelines on adult vaccination published by ministry of health and association of endocrinology and metabolism, dual vaccination (PCV13 + PPV23) is recommended for all diabetic patients without seeking additional risk factors [5, 6].

Those with cardiovascular disease, diabetes mellitus (DM), or chronic lung disease are at higher risk of complications of certain diseases such as vaccine-preventable pneumonia and influenza. In a meta-analysis of 33,000 patients with community-acquired pneumonia, the mortality rate among patients with DM was 1.3 times higher [7]. Despite all governmental policies and healthcare provider recommendations, the vaccination rate of patients with DM still remains far below the target. In a recent population-based study, the vaccination rate for pneumococcus was $22.8 \%$, whereas the vaccination rate for diabetic patients was $24.1 \%$ [8].

In $\mathrm{DM}$ or other major chronic conditions, vaccination is one of the most effective methods to control influenza transmission and reduce morbidity and mortality [9]. The underlying pathophysiological mechanisms of susceptibility to influenza in diabetic patients are not fully understood; however, the World Health Organization (WHO) recommends annual influenza vaccination. Impaired responsive response in the immune system has been proposed to be responsible for infection-related complications in diabetic patients [10]. Vaccination against influenza in patients with DM has been associated with a reduced risk of hospitalization and deaths from all causes, including pneumonia and influenza [9, 11].

In this study, it was aimed to determine the level of awareness on vaccines such as pneumococcus and influenza in DM patient population in Kocaeli.

\section{Methods}

This study was approved by the local ethics committee with project number KÜ GOKAEK 2019/16. DM patients who admitted to Kocaeli University Department of Endocrinology and Metabolic Diseases between January and February 2019 were included in this cross-sectional study. 202 patients over 18 years of age who gave informed consent for data collection and had no contraindications for vaccination were included in the study. Patients under 18 years of age, pregnant women, and patients with a history of allergic reaction to the vaccine and/or its components, active malignancy, severe neurological and psychiatric disorders were excluded from the study. After the routine diabetes outpatient control, information regarding patients' age, gender, and duration and treatment of diabetes was recorded. A survey questioning the vaccination status of the patients in the last year, attitude towards vaccines and awareness on vaccines was applied using the face-to-face interview method. The patients were questioned about their socio-demographic characteristics, as well as their previous vaccination status, who gave the recommendation for vaccination and, if any, the name of the vaccine they had. If the patients were against vaccination, the reason for this was discussed face to face.

\section{Statistical Analysis}

All statistical analyses were performed using IBM SPSS for Windows version 20.0 (SPSS, Chicago, IL, USA). Kolmogorov-Smirnov test was used to assess the assumption of normality. Numeric variables were expressed as mean \pm standard deviation and median $\left(25^{\text {th }}-75^{\text {th }}\right.$ percentile $)$. Categorical variables were summarized as counts (percentages). Since normality assumption did not hold, comparisons of numeric variables between groups were carried out using Mann-Whitney U test. An association between two categorical variables was examined by Chi-square test. All statistical analyses were carried out with 5\% significance and a two-sided $\mathrm{p}$-value $<0.05$ was considered statistically significant.

\section{Results}

A total of 202 [66 male (32.7\%) and 136 women (67.3\%) patients; with a mean age of $57.7 \pm 11.3$ years, and a mean duration of diabetes of $10.7 \pm 7.9$ years] who presented to the outpatient clinic of diabetes and met the inclusion criteria were recruited in the study. Majority of the patients (92.6\%) were type $2 \mathrm{DM}$ patients and only $3.5 \%$ of the whole population was being followed up with diet therapy alone. More than half of the patients had not been vaccinated before, and the majority of those vaccinated were vaccinated against influenza (87.8\%). The rate of those who had had pneumonia vaccine was very low, only $14.7 \%$. It was observed that the majority of the patients had received information about influenza and pneumonia from at least one source $(78.2 \%$, $71.8 \%$ respectively). The most common source of information for the patients was healthcare providers, consisting of doctors or nurses. While $83.2 \%$ of the patients stated that they would have the recommended vaccine, it was determined that only $52.5 \%$ of the patients finally had the vaccine (Table 1). Both genders had similar awareness on vaccination and a similar vaccination rate. 9 of 34 patients who answered "no" to the question of whether they could get the recommended vaccine had the vaccine at the end of the interview (Table 2). 
Table 1 Demographic data and vaccination rate in patients

\begin{tabular}{|c|c|c|c|}
\hline & & $\mathrm{n}$ & $\%$ \\
\hline \multirow[t]{2}{*}{ Sexuality } & Woman & 136 & 67.3 \\
\hline & Man & 66 & 32.7 \\
\hline \multirow[t]{2}{*}{ Type of Diabetes } & Type 1 & 15 & 7.4 \\
\hline & Type 2 & 187 & 92.6 \\
\hline \multirow[t]{4}{*}{ Treatment of Diabetes } & Diet & 7 & 3.5 \\
\hline & OAD & 99 & 49.0 \\
\hline & Insulin & 20 & 9.9 \\
\hline & $\mathrm{OAD}+$ Insulin & 76 & 37.6 \\
\hline \multirow[t]{2}{*}{ Have you ever been vaccinated before? } & Yes & 82 & 40.6 \\
\hline & No & 120 & 59.4 \\
\hline \multirow[t]{7}{*}{ Which vaccinations did you have? } & Influenza & 62 & 75.6 \\
\hline & Pneumonia & 3 & 3.7 \\
\hline & Hepatitis & 5 & 6.1 \\
\hline & Influenza + Pneumonia & 8 & 9.8 \\
\hline & Influenza + Hepatitis & 2 & 2.4 \\
\hline & Pneumonia + Hepatitis & 1 & 1.2 \\
\hline & All & 1 & 1.2 \\
\hline \multirow[t]{2}{*}{ Do you have information about the influenza vaccine? } & Yes & 158 & 78.2 \\
\hline & No & 44 & 21.8 \\
\hline \multirow{6}{*}{$\begin{array}{l}\text { Who did you get information about the influenza vaccine } \\
\text { from? }\end{array}$} & Doctor & 40 & 25.3 \\
\hline & Nurse & 111 & 70.3 \\
\hline & Television / Radio & 4 & 2.5 \\
\hline & Friend / Neighbor & 2 & 1.3 \\
\hline & Other & 1 & 0.6 \\
\hline & Missing & 44 & 21.8 \\
\hline \multirow[t]{2}{*}{ Do you have information about the pneumonia vaccine? } & Yes & 145 & 71.8 \\
\hline & No & 57 & 28.2 \\
\hline \multirow{6}{*}{$\begin{array}{l}\text { Who did you get information about the pneumonia vaccine } \\
\text { from? }\end{array}$} & Doctor & 32 & 22.1 \\
\hline & Nurse & 106 & 73.1 \\
\hline & Television / Radio & 2 & 1.4 \\
\hline & Friend / Neighbor & 2 & 1.4 \\
\hline & Other & 3 & 2.1 \\
\hline & Missing & 57 & 28.2 \\
\hline \multirow[t]{3}{*}{ Do you think diabetic patients should be vaccinated? } & Yes & 107 & 53.0 \\
\hline & No & 14 & 5.9 \\
\hline & I don't know & 81 & 40.1 \\
\hline \multirow[t]{6}{*}{ If yes, which vaccinations should they have? } & Influenza & 22 & 20.6 \\
\hline & Pneumonia & 8 & 7.5 \\
\hline & Hepatitis & 1 & 0.9 \\
\hline & Influenza + Pneumonia & 52 & 48.6 \\
\hline & All & 24 & 22.4 \\
\hline & Missing & 95 & 47.0 \\
\hline \multirow[t]{2}{*}{ Do you get the recommended vaccinations? } & Yes & 168 & 83.2 \\
\hline & No & 34 & 16.8 \\
\hline \multirow[t]{3}{*}{ If your answer is no, why not do it? } & Not effective & 5 & 14.7 \\
\hline & Has harmful effects & 5 & 14.7 \\
\hline & I do not think it is necessary & 24 & 70.6 \\
\hline \multirow[t]{2}{*}{ Have you had the recommended vaccine? } & Yes & 106 & 52.5 \\
\hline & No & 96 & 47.5 \\
\hline
\end{tabular}


Table 2 Situations of getting the recommended pneumococcal vaccine and barriers to vaccination

\begin{tabular}{|c|c|c|c|c|}
\hline & & \multicolumn{2}{|c|}{ Have you been vaccinated? } & \multirow[t]{2}{*}{$\mathrm{p}$ value } \\
\hline & & Yes & No & \\
\hline \multirow[t]{2}{*}{ Sexuality } & Woman & $67.0 \%(71)$ & $67.7 \%(65)$ & \multirow[t]{2}{*}{1.000} \\
\hline & Man & $33.0 \%(35)$ & $32.3 \%(31)$ & \\
\hline Age & Year & $60.5(53.0-66.0)$ & $58.0(50.5-63.0)$ & 0.171 \\
\hline Duration of diabetes & Year & $10.0(5.0-15.0)$ & $9.0(4.0-13.75)$ & 0.184 \\
\hline \multirow[t]{2}{*}{ Do you have information about the flu vaccine? } & Yes & $76.4 \%(81)$ & $80.2 \%(77)$ & \multirow[t]{2}{*}{0.630} \\
\hline & No & $23.6 \%(25)$ & $19.8 \%(19)$ & \\
\hline \multirow[t]{3}{*}{ Who did you get information about the flu vaccine from? } & Doctor & $23,5 \%(19)$ & $27,3 \%(21)$ & \multirow[t]{3}{*}{0.841} \\
\hline & Nurse & $71,6 \%(58)$ & $68,8 \%(53)$ & \\
\hline & Other & $4,9 \%(4)$ & $3,9 \%(3)$ & \\
\hline \multirow[t]{2}{*}{ Do you have information about the pneumonia vaccine? } & Yes & $74.5 \%(79)$ & $68.8 \%(66)$ & \multirow[t]{2}{*}{0.434} \\
\hline & No & $25.5 \%(27)$ & $31.3 \%(30)$ & \\
\hline \multirow[t]{3}{*}{ Who did you get information about the pneumonia vaccine from? } & Doctor & $25.3 \%(20)$ & $18.2 \%(12)$ & \multirow[t]{3}{*}{0.531} \\
\hline & Nurse & $70.9 \%(56)$ & $75.8 \%(50)$ & \\
\hline & Other & $3.8 \%(3)$ & $6.1 \%(4)$ & \\
\hline \multirow[t]{3}{*}{ Do you think diabetic patients should be vaccinated? } & Yes & $60.4 \%(64)$ & $44.8 \%(43)$ & \multirow[t]{3}{*}{0.015} \\
\hline & No & $2.8 \%(3)$ & $11.5 \%(11)$ & \\
\hline & I don't know & $36.8 \%(39)$ & $43.8 \%(42)$ & \\
\hline \multirow[t]{3}{*}{ If your answer is no, why? } & Not effective & $11.1 \%(1)$ & $16.0 \%(4)$ & \multirow[t]{3}{*}{0.506} \\
\hline & Has harmful effects & $22.2 \%(2)$ & $12.0 \%(3)$ & \\
\hline & I do not think it is necessary & $66.7 \%(6)$ & $72.0 \%(18)$ & \\
\hline
\end{tabular}

\section{Discussion}

Vaccination against pneumococcal infections in patients with DM has achieved significant reductions in morbidity and mortality, although sufficient immunization rates have not yet been achieved in Turkey. In this study, while the level of knowledge about and vaccination rate for influenza vaccine were quite high, it was difficult to say this for pneumonia vaccine. Pneumococcal vaccination rates in patients with DM were found to be lower than those in the European and USA population.

Although regular vaccination for influenza and pneumococcus is recommended for those with chronic diseases in the high-risk group in order to reduce mortality and morbidity, sufficient vaccination has been able to be achieved in only a small number of high-risk individuals worldwide [12]. According to the WHO data, they reported that the influenza vaccination rate should be at least $75 \%$ in high-risk groups [13]. Current data show that the influenza vaccination rate is approximately $50.3 \%$ in European countries, whereas this rate is lower in many Asian countries $[14,15]$. In the United States, the pneumococcal vaccination rate between the ages of 19-64 years was $23.0 \%$, while it was $63.6 \%$ over 65 years of age. The vaccination rate for whites aged 65 and over $(68.1 \%)$ was higher compared to those in blacks (50.2\%), Hispanics (41.7\%) and Asians (49.0\%) [16]. In a Turkish study conducted with DM patients in 2006, while influenza vaccination rate was $9.1 \%$, pneumococcal vaccination rate was only $0.1 \%$ [17]. In 2013, this rate increased up to $27 \%$ for influenza vaccine and to $9.8 \%$ for pneumococcal vaccine in diabetic patients [18]. In a recent Turkish study conducted in rural areas, $20 \%$ of the subjects were vaccinated with influenza vaccine and $11.1 \%$ with pneumococcal vaccine. Only $6.3 \%$ of all subjects had both vaccinations [19]. In a Turkish study conducted in the diabetic population in $2020,34.1 \%$ of the patients had the influenza vaccine and $9.9 \%$ the pneumococcal vaccine [20]. The vaccination rate of high-risk patient population has gradually increased in our country over the past years. In our study, while the rate of DM patients who had influenza vaccine was $87.8 \%$, this rate was $14.8 \%$ for pneumococcal vaccine. The rate of those who had both vaccinations was only $9.8 \%$. The rates for both vaccines were found to be above the average of our country. Such different vaccination rates may be related to the governmental health policies, the awareness level and socio-economic status of the societies.

Healthcare providers play an important role in advising and encouraging the administration of vaccines, particularly to vulnerable patients. Awareness of healthcare providers on effectiveness of vaccines strongly influences vaccination recommendations [21]. In a previous study, the rates of physicians having accurate information about influenza and pneumococcal vaccines were $58.1 \%$ and $53.5 \%$, respectively [22]. A study conducted in Pakistan revealed that 
$72.6 \%$ of doctors were not aware of the influenza vaccine recommendations and guidelines [23]. In a comprehensive Turkish study conducted with 12,574 healthcare providers, the rate of regular vaccination was found to be $6.7 \%$, while it was found that $55 \%$ of healthcare workers had never had a influenza vaccine [24]. In a study conducted with healthcare providers, awareness on pneumococcal and influenza vaccines was $58.7 \%$ and $86.2 \%$, respectively. The awareness on vaccines was highest among nurses with a rate of $70.2 \%$ [25]. In our study, it was determined that the patients mostly received information about both influenza and pneumococcal vaccine from the nurses. The higher rate in nurses than physicians as the source of information in this study may be related to several factors. First, diabetes education nurses have been in the same role for many years and second, the doctors in the diabetes outpatient clinic change every two months for the educational rotation.

There are many barriers behind the failure to reach the targeted levels in adult vaccination. In general, these include the lack of knowledge of physicians, inadequate access to healthcare, the cost of the vaccine, and the benefits and safety of the vaccines [22, 26]. In a study conducted with a Lebanese adult population, the only related barrier to regular influenza vaccination was found to be "considering the vaccine as unnecessary" [27]. In a German study, "fear of side effects" and "not requiring vaccination" were identified as the most important factors affecting influenza vaccination [28]. Social isolation and living alone in the elderly $>65$ years of age have been found to be an important barrier to vaccination [29]. In a cross-sectional study, significant barriers to vaccination were identified in $24 \%$ of diabetic patients and $42 \%$ of healthcare providers [30]. Doctors' advice for being vaccinated is one of the most important factors in achieving goals in adult vaccination [31]. Doctors in developing countries feel the need to update their knowledge, but this is not always achieved due to time and financial constraints. Increasing physicians' knowledge about and awareness on vaccines improves vaccination rates [18]. In our study, the rate of patients receiving information from doctors about influenza and pneumococcal vaccine did not exceed $25 \%$. The most common barrier for the patients to have the vaccine was found to be considering the vaccine as unnecessary. $26.4 \%$ of the patients who answered "no" to the question "Would you get the recommended vaccine?" had the pneumococcal vaccine as a result of being informed about the vaccine. $44.2 \%$ of the patients who answered "no" or "don't know" to the question "Do you think diabetes patients should be vaccinated?" had the pneumococcal vaccine as a result of being informed about the vaccine.

Several strategies have been proposed to increase vaccine coverage and vaccination rate in high-risk populations. Foremost, national and international scientific associations for high-risk diseases should provide stronger strategies for vaccination. Education of potential vaccine recipients in the at-risk group and promotion of vaccines is an important factor in raising awareness. Recent research has demonstrated the effectiveness of web-based apps that provide vaccine information via websites and social media. Promoting vaccination through community organizations and home visiting programs can increase vaccination rates. Strong vaccination programs should be developed as a governmental policy to increase vaccination rates. Reminding physicians the patients' vaccination status through medical records or electronic records is one of the most effective factors to increase vaccination rates. In our clinic, regular training meetings are held and informative posters are used to raise awareness on vaccines [30, 32, 33].

Severe acute respiratory syndrome coronavirus 2-related disease (COVID-19) has become one of the most alarming pandemics of recent times. COVID 19 has disrupted vaccination services in countries all over the world and has remained one of the most important barriers to vaccination services in recent times. COVID-19 is more severe in patients with DM, chronic lung and cardiovascular diseases, which are risk factors for pneumococcal infections [34]. Pneumococcal vaccines are known to reduce hospitalization rates for pneumonia in the adult population older than 65 years of age. This is important, as older people are the highest-risk group for death from COVID-19 [35]. Approximately $10 \%$ of deaths from COVID19 are thought to be caused by pneumococcal superinfection. Therefore, it is anticipated that potential secondary infections can be prevented by vaccination [36]. In an observational study involving 11,672 patients, people who received the pneumococcal vaccine during the same year were found to have a significantly lower risk of contracting COVID-19 [37]. Similarly, in a retrospective study involving a total of 27,201 patients, previous influenza vaccination was associated with a decrease in the number of positive COVID-19 tests and improved clinical outcomes [38]. As stated by WHO, pneumococcal vaccine reduces the risk of secondary bacterial infections, rather than protection against COVID-19 infection [39].

This study has a few limitations. Since the study was conducted in a tertiary health facility in Kocaeli, it may not reflect the country's actual vaccination rate. The low level of awareness of physicians may not reflect the data of primary and secondary care centers, as assistant doctors regularly rotate every two months in this center due to training. Finally, participants may differ socio-demographically and it is possible to differ in vaccination practices.

\section{Conclusion}

As shown by this study, the level of awareness on vaccines still remains to be a serious global problem, leading to low vaccination rates. Misinformation about vaccines can be a major cause of low vaccination rates. Vaccination rates can 
be improved by interventional efforts that support vaccination, such as electronic medical records, posters, short films, reminders for patients and service providers.

Funding The authors declare that they have not received any funding for this work.

Data availability All data and materials are available in our clinic and laboratory.

\section{Declarations}

Conflict of interest The authors declare that they have no competing interests.

\section{References}

1. American Diabetes Association (ADA). 4. Comprehensive medical evaluation and assessment of comorbidities: Standards of medical care in diabetes-2021. Diabetes Care. 2021;44:40-52.

2. Bridges CB, Woods L, Coyne-Beasley T. Advisory Committee on Immunization Practices (ACIP) recommended immunization schedule for adults aged 19 years and older - United States, 2013. MMWR Suppl. 2013;62(1):9-19.

3. Kyaw MH, Rose CE, Fry AM, Singleton JA, Moore Z, Zell $\mathrm{ER}$, et al. The influence of chronic illnesses on the incidence of invasive pneumococcal disease in adults. J Infect Dis. 2005;192:377-86.

4. Cassimos DC, Effraimidou E, Medic S, Konstantinidis T, Theodoridou M, Maltezou HC. Vaccination Programs for Adults in Europe, 2019. Vaccines. 2020;8:34.

5. TC. Sağglık Bakanlığı Riskli Grup Aşılama Genelgesi. 2016. Available from: https://asirehberi.saglik.gov.tr/genelgeler/risk-grubugenelgesi\#.

6. Diyabetik Birey Aşılama Rehberi. 2020. Available from: http:// temd.org.tr/admin/uploads/tbl_kilavuz/20200217142056-2020t bl_kilavuzd6c6d777e2.pdf.

7. Fine MJ, Smith MA, Carson CA, Mutha SS, Steadman SS, Weissfeld LA, et al. Prognosis and outcomes of patients with community-acquired pneumonia: a meta-analysis. JAMA. 1996;275:134-41.

8. Wang Y, Cheng M, Wang S, Wu F, Yan Q, Yang Q, et al. Vaccination coverage with the pneumococcal and influenza vaccine among persons with chronic diseases in Shanghai, China, 2017. BMC Public Health. 2020;20:1-9.

9. Remschmidt C, Wichmann O, Harder T. Vaccines for the prevention of seasonal influenza in patients with diabetes: Systematic review and meta-analysis. BMC Med. 2015;13:53.

10. Muller LMAJ, Gorter KJ, Hak E, Goudzwaard WL, Schellevis FG, Hoepelman AIM, et al. Increased risk of common infections in patients with type 1 and type 2 diabetes mellitus. Clin Infect Dis. 2005;41:281-8.

11. Casanova L, Gobin N, Villani P, Verger P. Bias in the measure of the effectiveness of seasonal influenza vaccination among diabetics. Prim Care Diabetes. 2016;10(6):398-406.

12. Sheldenkar A, Lim F, Yung CF, Lwin MO. Acceptance and uptake of influenza vaccines in Asia: A systematic review. Vaccine. 2019;37(35):4896-905.

13. World Health Organization. Vaccines against influenza WHO position paper-November 2012. Weekly Epidemiological Record= Relevé épidémiologique hebdomadaire. 2012;87(47):461-76.
14. Jorgensen P, Mereckiene J, Cotter S, Johansen K, Tsolova $\mathrm{S}$, Brown C. How close are countries of the WHO European Region to achieving the goal of vaccinating $75 \%$ of key risk groups against influenza? Results from national surveys on seasonal influenza vaccination programmes, 2008/2009 to 2014/2015. Vaccine. 2018;36:442-52.

15. Palache A, Oriol-Mathieu V, Abelin A, Music T. Seasonal influenza vaccine dose distribution in 157 countries (2004-2011). Vaccine. 2014;32:6369-76.

16. Williams WW, Lu P-J, O'Halloran A, Kim DK, Grohskopf LA, Pilishvili T, et al. Surveillance of Vaccination Coverage among Adult Populations - United States, 2015. MMWR Surveill Summ. 2017;66:1-28.

17. Biberoğlu K. Importance of adult immunization. Where is adult immunization in Turkey. actual medica. 2006;14:18-24.

18. Satman I, Akalin S, Cakir B, Altinel S, Comlekci A, Yurumez A, et al. The effect of physicians' awareness on influenza and pneumococcal vaccination rates and correlates of vaccination in patients with diabetes in Turkey: An epidemiological Study "diaVAX." Hum Vaccines Immunother. 2013;9:2618-26.

19. Guclu OA, Demirci H, Ocakoglu G, Guclu Y, Uzaslan E, Karadag M. Relationship of pneumococcal and influenza vaccination frequency with health literacy in the rural population in Turkey. Vaccine. 2019;37:6617-23.

20. Cennet A, Akin S, Aladağ N, Şimşek E. Pneumococcal, Influenza, Hepatitis B, and Tetanus Vaccination Rate and Vaccine Awareness in Patients with Type 2 Diabetes. Turk J Endocrinol Metab. 2020;24:327-34.

21. Pelullo CP, Della Polla G, Napolitano F, Di Giuseppe G, Angelillo IF. Healthcare Workers' Knowledge, Attitudes, and Practices about Vaccinations: A Cross-Sectional Study in Italy. Vaccines. 2020;8:148.

22. Romani MH, Musharrafieh UM, Lakkis NA, Hamadeh GN. Family physicians beliefs and attitudes regarding adult pneumococcal and influenza immunization in Lebanon. Fam Pract. 2011;28:632-7.

23. Ali I, Ijaz M, Rehman IU, Rahim A, Ata H. Knowledge, Attitude, Awareness, and Barriers Toward Influenza Vaccination Among Medical Doctors at Tertiary Care Health Settings in Peshawar, Pakistan-A Cross-Sectional Study. Front Public Heal. 2018;6:173.

24. Korkmaz N, Nazik S, Gümüştakım RŞ, Uzar H, Kul G, Tosun S, et al. Influenza vaccination rates, knowledge, attitudes and behaviours of healthcare workers in Turkey: A multicentre study. Int J Clin Pract. 2021;75:13659.

25. Evren H, Ünal Evren E, Özcem SB, Yazgan ZÖ, Barış SA, Yıldız F. The Knowledge Level of Hospital Staff about Influenza and Pneumococcal Vaccination. Cyprus J Med Sci. 2019;4(3):220-4.

26. Hershey CO, Karuza J. Delivery of Vaccines to Adults: Correlations with Physician Knowledge and Patient Variables. Am J Med Qual. 1997;12:143-50.

27. El Khoury G, Salameh P. Influenza Vaccination: A Cross-Sectional Survey of Knowledge, Attitude and Practices among the Lebanese Adult Population. Int J Environ Res Public Health. 2015;12:15486-97.

28. Bödeker B, Remschmidt C, Schmich P, Wichmann O. Why are older adults and individuals with underlying chronic diseases in Germany not vaccinated against flu? A population-based study BMC Public Health. 2015;15:1-10.

29. Wang Z, Fang Y, Ip M, Lau M, Lau JTF. Facilitators and barriers to completing recommended doses of pneumococcal vaccination among community-living individuals aged $\geq 65$ years in Hong Kong - a population-based study. Hum Vaccin Immunother. 2021;17:527-36.

30. Alvarez CE, Clichici L, Patricia Guzmán-Libreros A, NavarroFrancés M, Ena J. Survey of vaccination practices in patients with diabetes: A report examining patient and provider perceptions and barriers. J Clin Transl Endocrinol. 2017;9:15-7. 
31. Zimmerman RK, Santibanez TA, Janosky JE, Fine MJ, Raymund $\mathrm{M}$, Wilson SA, et al. What affects influenza vaccination rates among older patients? An analysis from inner-city, suburban, rural, and veterans affairs practices. Am J Med. 2003;114:31-8.

32. Cataldi JR, Kerns ME, O'Leary ST. Evidence-based strategies to increase vaccination uptake: a review. Curr Opin Pediatr. 2020;32:151-9.

33. Anderson EL. Recommended solutions to the barriers to immunization in children and adults. Mo Med. 2014;111:344-8.

34. Dinleyici EC, Borrow R, Safadi MAP, van Damme P, Munoz FM. Vaccines and routine immunization strategies during the COVID19 pandemic. Hum Vaccin Immunother. 2021;17:400-7.

35. Rossi PG, Ferroni E, Alegiani SS, Pitter G, Leoni O, Cereda D, et al. Survival of hospitalized COVID-19 patients in Northern Italy: A population-based cohort study by the ITACOVID19 Network. Clin Epidemiol. 2020;12:1337-46.

36. Thindwa D, Garcia Quesada M, Liu Y, Bennett J, Cohen C, Knoll $\mathrm{MD}$, et al. Use of seasonal influenza and pneumococcal polysaccharide vaccines in older adults to reduce COVID-19 mortality. Vaccine. 2020;38(34):5398-401.
37. Jehi L, Ji X, Milinovich A, Erzurum S, Rubin BP, Gordon S, et al. Individualizing Risk Prediction for Positive Coronavirus Disease 2019 Testing: Results From 11,672 Patients. Chest. 2020;158:1364-75.

38. Conlon A, Ashur C, Washer L, Eagle KA, Hofmann Bowman MA. Impact of the influenza vaccine on COVID-19 infection rates and severity. Am J Infect Control. 2021;S0196-6553(21):00089-94.

39. World Health Organization. Coronavirus disease (COVID-19) advice for the public: Mythbusters. 2021. Available from: https:// www.who.int/emergencies/diseases/novel-coronavirus-2019/ advice-for-public/myth-busters.

Publisher's Note Springer Nature remains neutral with regard to jurisdictional claims in published maps and institutional affiliations. 